\title{
Measure the success of smart growth based on ISM
}

\author{
Yue Huan ${ }^{1, a}$ \\ ${ }^{1}$ School of North China Electric Power University (Baoding), Baoding 071000, China \\ a896779907@qq.com
}

Keywords: Smart growth, ISM, The three E's.

\begin{abstract}
We choose urban development level to measure the success of smart growth. Then excavate a number of indicators considering the sustainability of the three E's. Due to the number of excessive indicators, we use the interpretative structural model (ISM) to determine the relationship between indicators. Finally, according to the results of ISM, we select 6 indicators covering the levels of economy, equality and environment to evaluate urban development level. Judge the smart growth by the value urban development level quantitatively. And finally, based on the evaluation system we have established, we have developed a number of proposals for the Charleston County.
\end{abstract}

\section{Introduction}

In order to measure the success of smart growth, we choose a series of indicators considering the conception of three $\mathrm{E}$ after further study of domestic and foreign literature. However, the relationship between all indicators is complex. So we use the Interpretation Structure Model (ISM) to select major indicators which influences the success of smart growth. Next, determine the quantitative relationship between the most influential indicators and smart growth.

Smart growth is a way of urban planning that provides a framework for making community development decisions. Smart growth network develops 10 basic principles which are flexible and adaptable, and are successfully applied to urban and suburban small towns. Despite of its increasing use, it is not known whether smart growth can affect physical activity successfully.

Our goal is to determine the indicators to measure the success of current smart growth and the relevant development plans. In the process of evaluation, we need to consider whether it meets the ten principles and three E's of sustainability---Economically prosperous, socially Equitable, and Environmentally Sustainable. We try to obtain indicators and use these indicators to analyze the program.

\section{Measure the success of smart growth based on ISM}

We select indicators of smart growth from economy, environment and social equity three aspects. Previous literature has shown that, as for economy, the success of smart growth is mainly affected by the income and expenditure of regional population; in terms of environment, air quality plays major role; as to social equity, the drop in crime and unemployment are good reflections to the success of smart growth. Therefore, we finally select 18 indicators: urban development index, cost of living index, GDP, income per capita, housing price, price level index, air quality index, sulfur dioxide emissions, nitrogen dioxide emissions, pollution particulates, percentage of population without health insurance coverage, vegetation coverage, factory number, unemployment rate, enrollment rate, education level, crime rate, and the number of families below the poverty line.

\section{Determine major indicators by ISM.}

The above indicators constitute the system set $\mathrm{T}$ of ISM, that is $\mathrm{T}=\{\mathrm{T} 1, \mathrm{~T} 2, \mathrm{~T} 3, \ldots, \mathrm{T} 18\}$. Next, we analyze the relationship between these indicators. First of all, we use adjacency matrix(M)to express the direct relationship between the indicators.

$$
\mathrm{M}=\left[\mathrm{m}_{\mathrm{ij}}\right]_{\mathrm{n} * \mathrm{n}}
$$


After several discussions, we establish adjacency matrix $\mathrm{M}$. And then we add the unit matrix I to the adjacency matrix $M$, to obtain matrix $(M+I)$. Next, we calculate $(M+I) n$ based on Boolean operation, and get the reachability matrix $\mathrm{R}$. $\mathrm{R}$ is calculated by the equation:

$$
\begin{gathered}
(\mathrm{M}+\mathrm{I}) \neq(\mathrm{M}+\mathrm{I})^{2} \neq(\mathrm{M}+\mathrm{I})^{3} \neq \ldots \neq(\mathrm{M}+\mathrm{I})^{\mathrm{k}}=(\mathrm{M}+\mathrm{I})^{\mathrm{k}+1} \\
\mathrm{R}=(\mathrm{M}+\mathrm{I})^{\mathrm{k}}
\end{gathered}
$$

After calculation by the Matlab software, $\mathrm{k}=3$. Reachability matrix $\mathrm{R}$ is determined, which is used to express all direct and indirect relationships between the indicators.

Thirdly, we define the reachable set $\mathrm{R}(\mathrm{Li})$ is a collection of elements of different columns in the reachability matrix $\mathrm{T}$, whose correspondence value to the element of same row is 1 ; similarly, we define the reachable set $\mathrm{Q}(\mathrm{Li})$ is a set of elements of different rows in the reachability matrix $\mathrm{T}$, whose correspondence value to the element of same column is 1 . When $R(L i)=R(L i) \cap Q(L i)$, which means that the element is for the layer, we remove it from the set of elements. After calculating one by one, we can divide the indicators by level one to one. Then arrange the reachability matrix based on the results above and obtain the ISM [1].

\section{Discussion of the result.}

According to the classification, we obtain multi-level structure chart of the smart growth evaluation indicators. It is showed below.

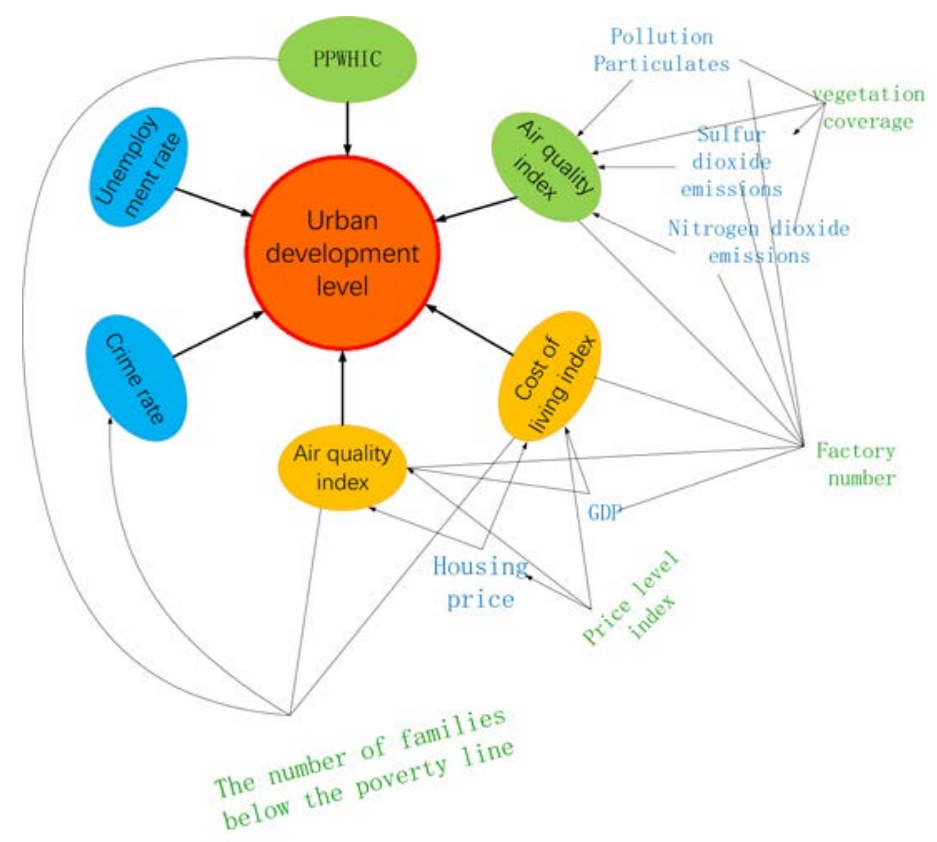

Figure 1 the ISM of the evaluating indicators

As can be seen from the figure above, the ISM divides evaluating indicators of smart growth into four levels. Taking the actual situation of urban development into account, we analyze the model further next.

The most basic factors (the lowest level) determining urban development level are Price level index, vegetation area, factory number and the number of family below the poverty line. They have indirect relationship with urban development level.

The third level includes the GDP, housing price and other factors, while the second layer includes five factors, such as income per capita, air quality index and so on. The elements of the two layers are strongly connected and highly interactive. In addition, it is found that these indicators in the third level is affected by those indicators in lowest level directly, and the indicators in second layer have direct influence on urban development level. As a conclusion, we can see that the degree of interaction between these indicators is relatively large. And if there is fluctuation of any element of any level, it will cause big change for the whole system.

The first level is urban development level, which means the success of smart growth is determined by urban development level. It is reasonable for us to measure the success of smart growth of a city 
according to urban development level. Because urban development level is mainly measured by income per capita, consumption level index, air quality index and so on, which appear in second layer and are able to reflect fully the degree of economic prosperity, social equity and environmental sustainability. Therefore, if a city carries out smart growth, it will make these six indicators' value change consequentially. Then measure the level of urban development of the city according to the changes of six indicators. If the level of development of the city increases, it shows that the smart growth of the city is successful.

In summary, the establishment of ISM of smart growth evaluation system, clearly excavates the relationships among the indicators. We use six indicators covering the concept of three E's to evaluate the change of urban development level, and then qualitatively analyze the success of the smart growth.

\section{Organization of the Text}

Based on the ISM we construct above, we judge the success of smart growth using the changes of urban development level. We only select the main indicators of the second level to assess the change in urban development level, because the indicators of third and the fourth levels have indirect impacts on the urban development level. Considering the three E's sustainability, we divide these six indicators into economy, environment, and fairness three aspects to study.

In terms of economic prosperity, there are two indicators. Income per capita reflects the level of economic development in a region. The higher the index, the more prosperous the region economic development. As for cost of living index, it reflects the change of per household (per person) consumption level in different periods, which expresses the economic level of a region.

As far as social equity, crime rate, it includes unemployment rate and the percentage of population without health insurance coverage. Crime rate can reflect the atmosphere and the justice in a region. The volatility of the unemployment rate shows the fairness of the government in the formulation of employment policies and Implementation. And the percentage of population without health insurance coverage can show the fairness of the treatment of urban residents.

As to Environmental sustainability, air quality index has great concern with it. Next, we design a evaluation system which is shown in Figure2.

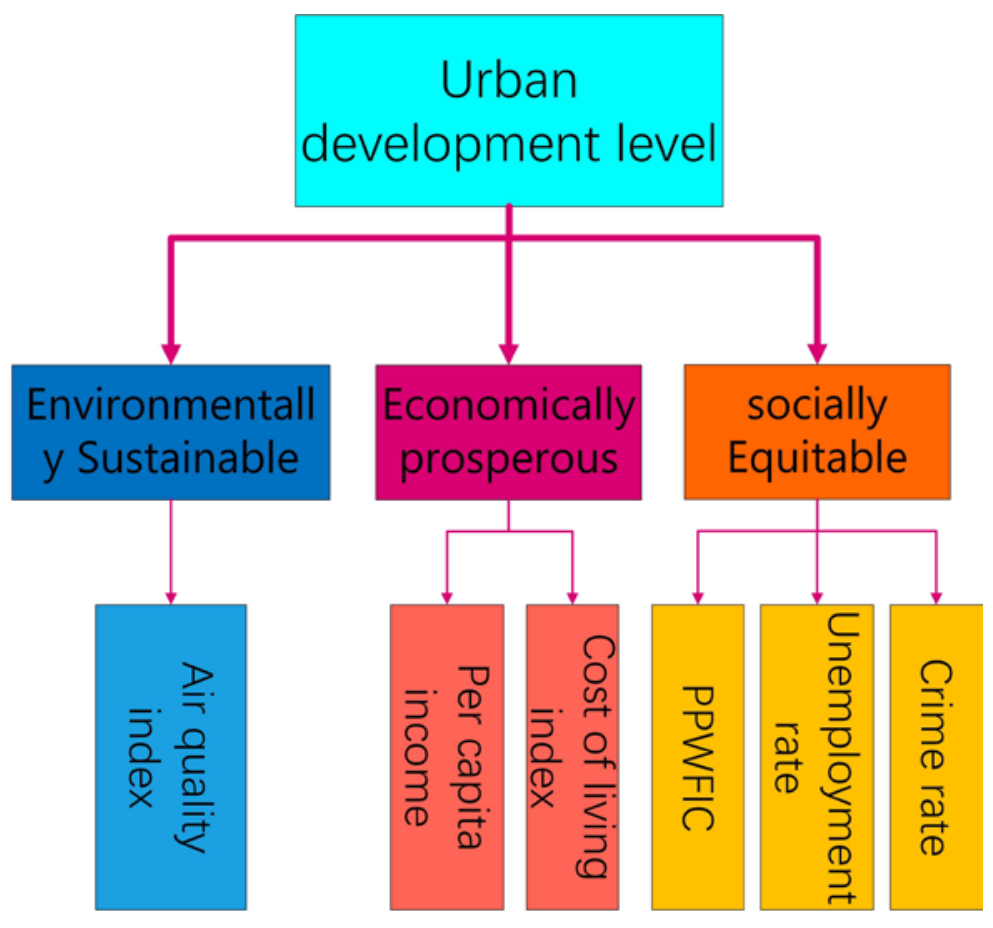

Figure 2 the evaluation system 


\section{Conclusions}

Finally, based on the evaluation system that we have established, we made the following suggestions for Charleston County from the location, economic advantages and social conditions.

1) Improve the health care laws and relevant agencies. Develop a comprehensive care model, which integrates primary care, acute care, long-term service and other service models together to provide high-quality care for the elderly and the disabled. In addition, it is necessary to improve the professional skills of staff. Effective management of health care database information is also needed, to improve the accessibility and usability of related websites.

2) Reduce pollutant emissions, and absorb existing air pollutants. Exhaust emissions after reaching the standard of purification through science and technology, or use clean energy, such as solar and wind. Create a unique industrial chain. On the other hand, increase vegetation coverage to use photosynthesis of green plants to absorb pollutants; At the same time, it is essential to improve people's awareness of environmental protection. Moreover, check the air quality regularly, and deal with problems in time [2,3].

3) Encourage enterprises to increase employment to create more job opportunities. Strengthen employment training to improve the quality of labor force. Improve the social security system, and reduce the possibility of crime. Develop relevant laws and regulations, and improve the efficiency of criminal procedure. Avoid repressive policies, to prevent the emergence of "iron fist" strategy in the central United States; strengthen gun control and reduce gun crime by cutting off the supply of illegal firearms; in addition, implement legal education and carry out legal activities [4].

\section{References}

[1] Mandal A, Deshmukh S G. Vendor selection using interpretive structural modelling (ISM)[J]. International Journal of Operations \& Production Management, 1994, 14(6): 52-59.

[2] Seattle OPCD - Economic Development Element, Mayor's Recommended Plan May 2016, http://www.seattle.gov/dpd/cs/groups/pan/@pan/documents/web_informational/p 2450584.pdf

[3] Strategic Goal 1 | HHS.gov, https://www.hhs.gov/about/strategic-plan/strategic-goal-1/\#obj_a

[4] Five Ways to Reduce Crime | Urban Institute, http://www.urban.org/urban-wire/five-ways-reduce-crime 